As well as having these direct ill-effects, the acids can also cause damage indirectly. For example, acid rain leaches aluminium from some soils which then runs into lakes and streams, where it can be highly toxic. Similarly, such heavy-metals as mercury, cadmium, manganese, and lead, are rendered far more toxic by acid than neutral or basic water. Acidity encourages the formation of compounds in which organic molecules and heavy-metals have combined chemically, producing substances which are highly toxic to most forms of aquatic life. As the most sensitive creatures die, so do other life-forms which depend on them for food. In the end the whole ecology of the lake is altered.

Acid precipitation also produces direct ill-effects on buildings and other structures the railway lines in the Katowice area of Poland have become so corroded by it that strict speed-limits have to be enforced. Stone buildings eventually begin to crumble and disintegrate, and paint-work blisters. The economic effects of the corrosion caused by sulphur and nitrogen oxides have been estimated at thousands of millions of dollars a year.

The effects on forestry are more controversial, and in spite of many studies scientists do not agree on exactly how acid rain affects forests. However, the role of aluminium and heavy-metals is suspected. In addition, acid rain may damage forests by leaching out other metals, such as magnesium and calcium, which are essential for forest growth.

Finally, acidity brought in precipitation is beginning to percolate through to ground-water reserves. Thus for example a survey on Sweden's west coast recently found that $49 \%$ of drinking wells were acidic--causing corrosion in pipes, foul-tasting water, and diarrhoea.

The acid precipitation situation is already critical in several respects and, as more and more countries turn to increased uses of coal for electricity production, there is a very real danger that things could worsen drastically. Only energy conservation and the application of known sulphur-pollution prevention technologies at new coalfired power-stations seem likely to prevent acid rain from becoming a major ecological catastrophe.

PaUl EVAN REss*
Senior Regional Information Officer
United Nations Environment Programme
Palais des Nations
1211 Geneva 10
Switzerland.

\section{Winston Churchill Travelling Fellowships}

Next year about one hundred fortunate people will be given the opportunity to travel almost anywhere in the world they may wish. They will have to prove that their work and interests could benefit from experience overseas, and that also in other respects they would be suitable for the award of a Winston Churchill Travelling Fellowship.

There are no particular educational or professional qualifications needed for application, no age restrictions,

\footnotetext{
*Now retired and living at 19 Avenue du Budé, 1211 Geneva, Switzerland.-Ed.
}

and all UK citizens are equally eligible. Churchill Fellows do, however, have to indicate how they propose to make use of their knowledge for the benefit of others on their return to the United Kingdom. The categories in which awards are offered for 1983 include emergency services of various kinds, natural history and conservation of local environment, and sewage, water, and flood-control, workers.

If you would like an application form and explanatory leaflet, just send your name and address on a postcard to:

\author{
Winston Churchill Memorial Trust \\ 15 Queen's Gate Terrace \\ London SW7 5PR, England, UK.
}

\section{The Journal of Arid Environments}

A forum for multidisciplinary dialogue in the fields indicated by its title, the Journal of Arid Environments (published by Academic Press, London, England, UK) was launched in 1978 to provide an outlet for the publication of original scientific and technological research and, simultaneously, to publish comprehensive reviews that should be intelligible to advanced students, technologists, administrators, and research workers, whatever their specializations and disciplines.

There is no single answer to the problems of the arid regions: these result mainly from increasing human populations, overgrazing by domestic stock, salinization, the felling of trees for firewood, and soil erosion. The wisest solutions vary according to local circumstances, including the cultural and religious attitudes of the indigenous peoples. Although science may point the way in which development can best proceed, administrators often have little idea either of the knowledge currently available or of how to apply it. The Journal provides an authoritative work of reference presenting new ideas, scientific facts, and guidance in how to apply them. Book reviews and technical notes increase the number of topics covered, and help to maintain a broad approach.

The ecosystems of arid environments are fragile and vulnerable to misuse. Social and geographical studies are, therefore, of more than mere academic interest. They illustrate the causes of desert expansion and indicate ways in which arid zones may be developed for the benefit of their inhabitants without engendering environmental deterioration. The solutions to social and economic problems can sometimes be simpler than is generally realized. For instance, one recent article drew attention to the fact that it might be more profitable to invest resources in the production of better-quality stock, which would be able to withstand a heavy trypanosome infection, than to spend the same amount of money and effort in attempting to achieve improved control of tsetse-flies (Glossina spp.), vectors of African sleepingsickness and 'nagana' of horses and cattle.

Other recent contributions outline methods of managing finite groundwater supplies, or deal with Islamic water laws and oasis settlement, nomadism and pasturalism, wildlife conservation and land-use, the production of energy from salt and from solar radiation, weather modification, and remote-sensing from satellites.

The world's arid biomes are among the most inhospitable of all terrestrial environments. The adaptations of 